\title{
SUPERABSORBENT TOY POSES A HEALTH HAZARD TO CHILDREN
}

Singapore Med J 2013; 54(8): 473 doi:10.11622/smedj.2013159

It has been estimated that about $40 \%$ of foreign body ingestions in children go unwitnessed. ${ }^{(1)}$ It is not uncommon for children to swallow small toys or parts of toys. Most swallowed objects go through the digestive tract and get passed out uneventfully. However, this is not the case if superabsorbent polymer products were to be ingested, as they rapidly absorb water and significantly expand within hours.

A Chinese girl aged 2 years and 5 months presented to our Emergency Department after an alleged history of having swallowed two superabsorbent polymer balls about eight hours before arrival at the hospital. The patient was not vomiting and did not have any abdominal pain. Her plain radiograph did not demonstrate any radiopaque foreign body. There were no radiological features suggestive of intestinal obstruction. The patient was admitted for observation for 24 hours, and has been well for a week following her discharge.

We reviewed the existing literature on this product and found that Zamora et $\mathrm{al}^{(2)}$ had reported the case of an 8-month-old infant who developed intestinal obstruction secondary to the ingestion of a similar expandable toy, 'Water Balz' (Fig. 1), in Texas last September, which required surgical management. This case led to a voluntary recall of the superabsorbent polymer toy in Canada and the United States of America via the Consumer Product Safety Commission and Health Canada. Zamora et $\mathrm{al}^{(2)}$ also studied the growth rate of these superabsorbent polymer balls in pure water. The experiment highlighted the salient point that within six hours, the ball could increase to a size that completely occludes the lumen of a child's small intestine. Zamora et al's study is also highly useful in demonstrating how this particular toy can behave in the intestines of a child following inadvertent ingestion.

These findings should alert emergency physicians and paediatric surgeons attending to children who have allegedly ingested such toys to actively monitor the patient for signs and symptoms of intestinal obstruction. Parents should also be aware of the potential implications and not dismiss such cases as an innocuous ingestion of a seemingly small foreign body. Additionally, there is the potentially fatal health hazard of choking on one of these superabsorbent toys, as there is the risk of these expanding toys obstructing the small respiratory airways of children.

Our research also revealed other similar products in the Singapore market. The Magic Grow Dino Egg (Fig. 2) resembles a small candy egg, which hatches when placed in water. A toy dinosaur lies within each egg and it can grow to impressive sizes after being submerged in water over time. These toys are widely popular among preschoolers and primary school-going children in Singapore.

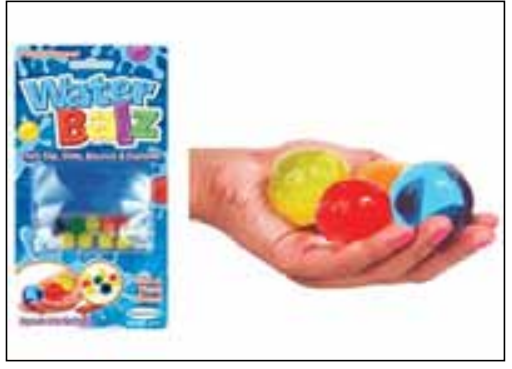

Fig. 1 Photograph shows a 'Water Balz' superabsorbent polymer toy, which was swallowed by 8 -month-old infant [image courtesy of DuneCraft Inc].

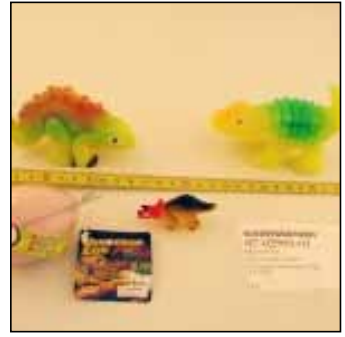

Fig. 2 Photograph shows a 'Magic Grow Dino Egg', which grows significantly in size when placed in water [image courtesy of http://unsafeproducts.eu/wp/wp-content/uploads/2011/01/2007w39_29-3f.jpg].

If these superabsorbent toys are made in such a way that they disintegrate due to the effect of gastric and/or intestinal juices on the chemicals present within the toys (e.g. polyacrylamide), then these toys can be deemed safe for children. The current products can be easily mistaken for candies due to their small size and attractive colours. This letter serves to highlight the potential health hazards of these superabsorbent polymer toys in small children. We strongly recommend a review of the sale of these superabsorbent polymer toys in Singapore.

\section{Yours sincerely,}

Grace Hui Min Tan', Joyce Horng Yiing Chua ${ }^{2}$, Kannan Laksmi Narasimhan²

${ }^{1}$ Yong Loo Lin School of Medicine, National University of Singapore, '2Department of Paediatric Surgery, KK Women's and Children's Hospital, Singapore. Joyce.Chua.HY@kkh.com.sg

\section{References}

1. Dahshan A. Management of ingested foreign bodies in children. J Okla State Med Assoc 2001; 94:183-6.

2. Zamora IJ, Vu LT, Larimer EL, Olutoye OO. Water-absorbing balls: a "growing" problem. Pediatrics 2012; 130:e1011-4. Epub September 17, 2012. 